\title{
PENGARUH BRAND AWARENESS TERHADAP KEPUTUSAN PEMBELIAN PADA PT GRAMEDIA ASRI MEDIA CABANG CINERE MALL DEPOK
}

\author{
Wiwin Wianti ${ }^{1}$, Wangsit Supeno ${ }^{2}$, Ira Karina Putri ${ }^{3}$ \\ Universitas Bina Sarana Informatika \\ Jalan Kamal Raya No.18, Ringroad Barat, Cengkareng, Jakarta Barat, Indonesia \\ 1wiwin.win@bsi.ac.id, ${ }^{2}$ wangsit.wss@bsi.ac.id, ${ }^{3}$ irakarina25@gmail.com
}

\begin{abstract}
Gramedia Asri Media is a company that specializes in retail that offers best books from various publishers, as well as school supplies products and an office that is best quality. PT Gramedia Asri Media trying continue to create a the brand awareness to public, In order to become the dominant choice in their purchasing choices. The study be conducted for determine how big influence the brand awareness of purchasing decisions. The method of this study used by quantitative method with Independent variables are Brand Awareness and the dependent variabel is purchasing decision and with sample of 30 respondents. The sampling technique used in this study is Sample Random Sampling. The method of this study used by methods observation, methods interview, methods questionnaire, and atudy documentation. Methods of data analysis used in this correlation coefficient analysis methods, determination coefficient, and simple linear regression analysis. Data processing was performed by using SPSS 23 software for Windows. Through the test R brand awareness has a strong relationship to the purchase decision. The influence of brand awareness on purchasing decision is $60,9 \%$ and the rest is $39,09 \%$ influenced by other factors not examines like brand image, promotion, quality of service and others. Each increase of one scala Brand Awareness will raise the Purchase Decision by 0,804 .
\end{abstract}

Keywords: Brand Awareness and Purchasing Decision

\section{PENDAHULUAN}

Seiring dengan perkembangan jaman yang didukung dengan berkembangnya teknologi yang semakin canggih berdampak pada persaingan bisnis yang semakin ketat. Oleh karena itu, untuk dapat menyikapi hal tersebut para pelaku usaha harus mampu mengambil kebijakan-kebijakan yang tepat untuk menciptakan posisi produk yang kuat dibenak pelanggannya. Fenomena yang ada telah membuat para pengusaha menyadari suatu kebutuhan untuk mengekspolitasi sepenuhnya aset-aset mereka. Salah satu aset untuk mencapai keadaan tersebut adalah merek. Merek memegang peran penting dalam 
pemasaran. Merek juga aset terbesar bagi perusahaan, karena merek yang sudah dikenal di pasar akan diingat dalam benak konsumen. Tingkat kesadaran konsumen terhadap suatu merek (brand awareness) sangatlah penting, karena adanya brand awareness yang tinggi diharapkan kapanpun kebutuhan muncul, brand tersebut yang akan diingat yang selanjutnya dijadikan pertimbangan berbagai alternatif dalam pengambilan keputusan. Buying decision (keputusan pembelian) merupakan suatu tahap dalam proses pengambilan keputusan pembeli dimana konsumen benar-benar membeli. Salah satu faktor untuk terjadinya buying decision (keputusan pembelian) adalah konsumen menyadari akan suatu merek yang telah mereka ingat dibenaknya. PT Gramedia Asri Media adalah perusahaan yang bergerak dalam bidang ritel yang menawarkan beragam buku dari penerbit-penerbit terbaik, produk pelengkapan sekolah dan perlengkapan kantor yang berkualitas terbaik. PT Gramedia Asri Media berusaha terus untuk menciptakan sebuah brand awareness atau kesadaran akan merek kepada masyarakat, agar menjadi satu-satunya merek yang dikenal dan diingat apabila masyarakat mengingat toko buku. Pada tahun 2019, Gramedia menjadi Top Brand Awared For Teens Index dalam kategori ritel toko buku, yang artinya menjadi satu-satunya yang paling dikenal dan menjadi sebuah pilihan utama dalam berbelanja kebutuhan sekolah, kantor, serta buku-buku bacaan.

\section{KAJIAN TEORITIS}

\subsection{Pengertian Brand / Merek}

Menurut Asosiasi Pemasaran Amerika dalam Hery (2019:90) mendefinisikan "merek (brand) sebagai nama, istilah, tanda, simbol, atau rancangan, atau kombinasi dari semuanya, yang dimaksudkan untuk mengidentifikasi barang atau jasa penjual atau kelompok penjual dan untuk mendiferensiasikannya dari barang atau jasa pesaing".

Menurut Kotler dan Amstrong dalam (Krisnawati, 2016) "Merek adalah nama, istilah,

tanda, simbol, desain atau kombinasi keseluruhannya, yang ditujukan untuk mengidentifikasikan barang atau jasa yang ditawarkan perusahaan sekaligus sebagai diferensiasi produk".

Menurut (Arief, Suyadi, \& Sunarti, 2017) "merek adalah nama, istilah, tanda, simbol, logo, atau kemasan dengan maksud untuk mengidentifikasikan barang atau jasa dari seseorang maupun kelompok penjual tertentu". 


\subsection{Pengertian Brand Awareness (Kesadaran Merek)}

Menurut Durianto dalam (Utomo, 2017) kesadaran merek menunjukkan kesanggupan seorang calon pembeli untuk mengenali atau mengingat kembali bahwa suatu merek merupakan bagian dari kategori produk tertentu. Brand awareness memerlukan adanya continum rangung (jangkauan kontinum) dari perasaan yang tidak pasti bahwa suatu merk tertentu telah dikenal sebelumnya, sehingga konsumen percaya bahwa produk tersebut merupakan satu-satunya merek dalam suatu kelompok produk. Jangkauan kontinum dapat diwakili oleh satu tingkatan brand awareness yang berbeda yang dapat digambarkan dalam suatu piramida berikut ini:

\section{Gambar II.1}

\section{Piramida Brand Awareness}

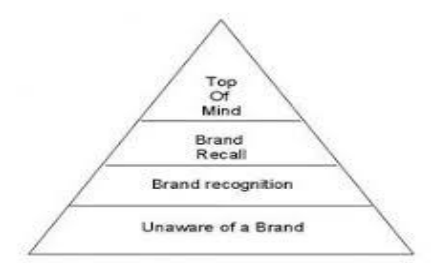

Sumber : Durianto dalam (Utomo, 2017)

Penjelasan mengenai piramida brand awareness dari tingkat terendah sampai tingkat tertinggi adalah:

\section{Unware of brand}

Merupakan tingkat yang paling rendah dalam piramida kesadaran merek di mana konsumen tidak menyadari akan adanya suatu merek.

\section{Brand recognition}

Merupakan tingkat minimal dari kesadaran merek. Hal ini penting pada saat seorang pembeli memilih suatu merek pada saat melakukan pembelian.Pengakuan merek, didasarkan suatu tes pengingatan kembali lewat bantuan.Pengenalan merek adalah tingkat minimal dari kesadaran merek, hal ini penting khususnya ketika seorang pembeli memilih suatu merek pada saat pembelian.

3. Brand recall

Pengingatan kembali merek didasarkan pada permintaan seseorang untuk menyebutkan merek tersebut dalam suatu kelas produk. Hal ini diistilahkan dengan pengingatan kembali tanpa bantuan, karena berbeda dari tugas pengenalan, responden tidak perlu dibantu untuk memunculkan merek tersebut.

\section{Top of Mind}

Merupakan tingkat tertinggi dari kesadaran merek. Apabila seseorang ditanya secara langsung tanpa diberi bantuan pengingatan dan ia dapat menyebutkan satu nama merek, 
maka merek yang paling banyak disebutkan pertama kali merupakan puncak pikiran, dengan kata lain, merek tersebut merupakan merek utama dari berbagai merek yang ada di dalam benak konsumen. Posisi pengingatan kembali yang lebih kuat dari kesadaran puncak pikiran adalah merek dominan, yaitu merek yang menempati posisi sebagai satu-satunya merek yang diingat kembali oleh responden dengan presentase tinggi.

\subsection{Pengertian Buying Decision (Keputusan Pembelian)}

Menurut (Roisah,Riris dan Riana, 2016) “Keputusan pembelian merupakan kegiatan individu yang secara langsung terlibat dalam pengambilan keputusan untuk melakukan pembelian terhadap produk yang ditawarkan oleh penjual".

Menurut (Syahril, 2017) Keputusan pembelian adalah pemilihan satu dari dua atau lebih alternatif pilihan keputusan pembelian, artinya bahwa seseorang dapat membuat keputusan, haruslah tersedia beberapa alternatif pilihan.

Menurut Schiffman, Kanuk dalam (Paregkuan, Tumbel, \& Wenas, 2014) keputusan pembelian adalah pemilihan dari dua atau lebih alternatif pilihan keputusan pembelian, artinya bahwa seseorang dapat membuat keputusan, harus tersedia beberapa alternatif pilihan.

Menurut Kotler dan Armstrong dalam (Mamahir, Soegoto, \& Tumbuan, 2015) Keputusan pembelian merupakan proses kejadian: pengenalan masalah kebutuhan, pencarian informasi, evaluasi alternatif, keputusan pembelian dan perilaku pasca pembelian.

\subsection{Faktor-faktor yang Mempengaruhi Keputusan Pembelian}

Menurut Kotler dan Keller dalam (Lubis \& Hidayat, 2017) menyatakan faktor-faktor yang mempengaruhi keputusan pembelian terdiri atas:

1. Faktor Budaya, Budaya mempunyai pengaruh yang paling luas dan paling dalam terhadap keputusan pembelian. Pemasar harus memahami peran yang dimainkan oleh kultur, subkultur, dan kelas sosial pembeli.

2. Faktor Sosial, Keputusan pembelian juga akan dipengaruhi oleh faktor sosial seperti kelompok acuan, keluarga, peran, dan status sosial dari konsumen

3. Faktor Pribadi, Keputusan pembelian juga dipengaruhi oleh usia dan tahap siklus hidup pembeli, pekejaan dan lingkungan ekonomi, kepribadian, konsep diri serta gaya hidup dan nilai.

4. Faktor Psikologis, Pilihan pembelian seseorang juga dipengaruhi oleh faktor psikologis yang utama, yaitu motivasi, persepsi, proses pembelajaran, serta kepercayaan.

\subsection{Peranan dalam Keputusan Pembelian}

Menurut Abdullah \& Tantri (2018:124) lima peran yang dimainakan orang dalam keputusan pembelian: 
1. Pencetus ide (initiator) yaitu orang yang pertama kali mengusulkan untuk membeli produk atau jasa tertentu.

2. Pemberi Pengaruh (influence) yaitu orang yang pandangan atau pendapatnya mempengaruhi pembelian.

3. Pengambilan Keputusan (decider)

Orang yang memutuskan setiap komponen dalam keputusan pembelian: apakah membeli, apa yang dibeli,bagaimana membeli, atau dimana membeli.

4. Pembeli (buyer)

Orang yang melakukan pembelian actual.

5. Pemakai Orang yang mengonsumsi atau menggunakan produk atau jasa yang dibeli.

\subsection{Tahap-tahap dalam Proses Keputusan Pembelian}

\section{Gambar II.2}

Model Proses Pembelian Lima Tahap

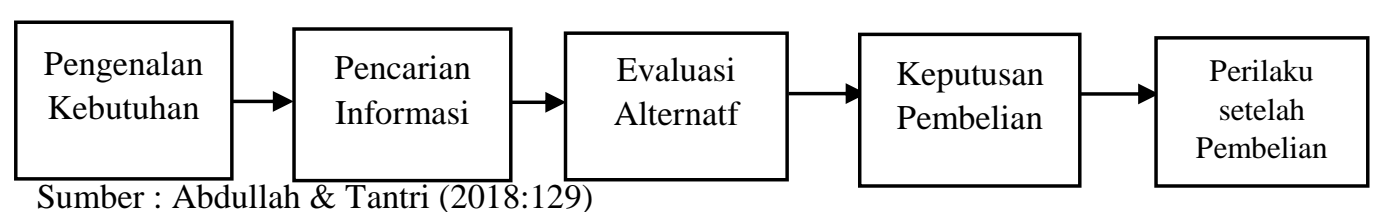

Menurut Abdullah \& Tantri (2018:130) ada lima tahap dalam proses keputusan pembelian, yaitu:

1. Pengenalan kebutuhan

Proses pembelian dimulai ketika pembeli menyadari adanya masalah atau kebutuhan. Pembeli merasakan adanya perbedaan antara keadaan aktual dengan keadan yang diinginkannya. Kebutuhan ini dapat dipicu adanya stimuli internal maupun eksternal.

2. Pencarian informasi

Seorang konsumen yang bergerak oleh stimuli akan berusaha mencari lebih banyak informasi.

3. Evaluasi alternatif

Terdapat beberapa proses evaluasi keputusan. Sebagian besar model terbaru dari proses evaluasi konsumen berorientasi secara kognitif, yaitu mereka menganggap bahwa konsumen sebagaian besar melakukan penelitian produk secara sadar dan rasional. Konsep dasar akan membantu kita memahami proses evaluasi konsumen. Kita bias melihat bahwa konsumen berusaha memuaskan suatu kebutuhan. Konsumen tersebut mencari manfaat (benefit) dari solusi produk. Konsumen memandang setiap produk sebagai sekumpulan atribut ( $a$ bundle of attributes) dengan kemampuan yang berbeda-beda dalam memberikan manfaat yang dicari da memuaskan kebutuhan tersebut. 
4. Keputusan pembelian

Dalam tahap evaluasi, konsumen membentuk preferensi di antara merek-merek dalam kelompok pilihan. Konsumen juga membentuk minat pembelian untuk membeli merek yang paling disukai.

5. Perilaku setelah pembelian

Setelah membeli produk, konsumen akan merasakan tingkat kepuasan atau ketidakpuasan tertentu. Konsumen juga akan melakukan tindakan purnabeli dan menggunakan produk tersebut.

\section{METODE PENELITIAN}

\subsection{Operasional Variabel}

\section{Table III.1}

Operasional Variabel

\begin{tabular}{|c|c|c|c|c|}
\hline Variabel & Dimensi & Indikator & Jenis Data & Skala \\
\hline $\begin{array}{l}\text { Brand } \\
\text { Awareness }\end{array}$ & $\begin{array}{ll}\text { Unware } & \text { of brand } \\
\text { (tidak } & \text { menyadari } \\
\text { merek) } & \end{array}$ & $\begin{array}{l}\text { Paling rendah dalam piramida kesadaran } \\
\text { merek, dimana konsumen tidak } \\
\text { menyadari merek }\end{array}$ & Oridinal & Likert \\
\hline \multirow[t]{3}{*}{ Variabel X } & $\begin{array}{l}\text { Brand recognition } \\
\text { (pengenalan merek) }\end{array}$ & $\begin{array}{l}\text { Tingkat minimal kesadaran merek } \\
\text {,dimana pengenalan suatu merek muncul } \\
\text { lagi setelah dilakukan pengingatan } \\
\text { kembali lewat bantuan (aided recall) }\end{array}$ & Oridinal & Likert \\
\hline & $\begin{array}{l}\text { Brand Recall } \\
\text { (peningkatan kembali } \\
\text { terhadap merek) }\end{array}$ & $\begin{array}{l}\text { Pengingatan kembali suatu merek tanpa } \\
\text { bantuan }\end{array}$ & Oridinal & Likert \\
\hline & $\begin{array}{l}\text { Top of mind (puncak } \\
\text { pikiran) }\end{array}$ & $\begin{array}{l}\text { Merek yang disebutkan pertama kali oleh } \\
\text { konsumen atau yang pertama kali muncul } \\
\text { dalam benak konsumen }\end{array}$ & Oridinal & Likert \\
\hline \multirow[t]{4}{*}{$\begin{array}{l}\text { Keputusan } \\
\text { Pembelian } \\
\text { Variabel Y }\end{array}$} & Pengenalan masalah & $\begin{array}{l}\text { Proses pembelian dimulai ketika pembeli } \\
\text { mengenali masalah atau kebutuhan. } \\
\text { Kebutuhan ini dapat dipicu oleh stimuli } \\
\text { internal maupun eksternal }\end{array}$ & Oridinal & Likert \\
\hline & Pencarian informasi & $\begin{array}{l}\text { Seorang konsumen yang bergerak oleh } \\
\text { stimuli akan berusaha mencari lebih } \\
\text { banyak informasi }\end{array}$ & Oridinal & Likert \\
\hline & Evaluasi alternatif & $\begin{array}{l}\text { Beberapa konsep dasar akan membantu } \\
\text { kita memahami proses evaluasi konsumen }\end{array}$ & Oridinal & Likert \\
\hline & Keputusan pembelian & $\begin{array}{l}\text { Konsumen membentuk preferensi di } \\
\text { antara merek-merek pada kelompok } \\
\text { pilihan }\end{array}$ & Oridinal & Likert \\
\hline
\end{tabular}




\begin{tabular}{|l|lr|l|l|l|}
\hline \begin{tabular}{|l|l|l|l|} 
Perilaku setelah \\
pembelian
\end{tabular} & $\begin{array}{l}\text { Setelah membeli produk, konsumen akan } \\
\text { merasakan tingkat kepuasan atau } \\
\text { ketidakpuasan tertentu }\end{array}$ & Oridinal & Likert \\
\hline
\end{tabular}

\subsection{Uji Instrumen Penelitian}

\section{Uji Validitas}

Menurut (Nurhidayati \& Yuliantari, 2018) Uji validitas digunakan untuk mengetahui seberapa cermat suatu instrumen atau item-item dalam mengukur apa yang ingin diukur. Item kuesioner yang tidak valid berarti tidak dapat mengukur apa yang ingin diukur sehingga hasil yang didapat tidak dapat dipercaya, sehingga item yang tidak valid harus dibuang.

Cara mencari nilai korelasi adalah sebagai berikut:

$$
\mathrm{r}=\frac{n(\Sigma X 1 Y 1)-(\Sigma X 1)(\Sigma Y 1)}{\sqrt{\left[n\left(\Sigma X 1 \Sigma^{2}\right)-(\Sigma X 1)^{2}\right]\left[n \Sigma Y 1^{2}-(\Sigma Y 1)^{2}\right]}}
$$

Sumber: Sugiyono (2013:248)

Keterangan:

$\mathrm{r} \quad=$ Koefisien korelasi Pearson's Product Moment

$\mathrm{N}=$ Jumlah individu dalam sampel

$\mathrm{X} \quad=$ Angka mentah untuk variabel $\mathrm{x}$

$\mathrm{Y} \quad=$ Angka mentah untuk variabel $\mathrm{y}$

$\Sigma \mathrm{x} \quad=$ Jumlah skor variabel $\mathrm{x}$

$\Sigma \mathrm{y} \quad=$ Jumlah skor untuk variabel $\mathrm{y}$

$\Sigma \quad=$ Jumlah kuadrat masing-masing skor $\mathrm{x}$

$\Sigma \quad=$ Jumlah kuadrat masing-masing skor $\mathrm{y}$

$\Sigma x y=$ Jumlah skor perkalian variabel $\mathrm{x}$ dan $\mathrm{y}$

Teknik pengujian yang sering digunakan para peneliti untuk uji validitas adalah menggunakan Correlated Item - Total Correlation. Analisis ini dengan cara mengkorelasikan masing-masing skor item dengan skor total. Skor total adalah penjumlahan dari keseluruhan item. Item-item pertanyaan yang berkorelasi signifikan dengan skor total menunjukkan item-item tersebut mampu memberikan dukungan dalam mengungkap apa yang ingin diungkap. Valid Jika $r$ hitung $\geq r$ tabel (uji 2 sisi dengan sig. 0,1) maka instrumen atau item-item pertanyaan berkorelasi signifikan 
terhadap skor total (dinyatakan valid). dan nilai $\mathrm{r}$ tabel dicari dengan menggunakan tingkat signifikasi 0,1 dengan uji sisi 2 dan $\mathrm{df}=\mathrm{n}-2$.

\section{Uji Reliabilitas}

Uji reliabilitas adalah sejauh mana hasil pengukuran dengan menggunakan objek yang sama, akan menghasilkan data yang sama menurut Sugiyono (2013:27). Untuk uji reabilitas digunakan metode teknik perhitungan reliabilitas yang digunakan dalam penelitian ini yaitu metode Internal Consistency Reliability dengan menggunakan koefisien reliabilitas Alpha Cronbach $(\alpha)$, hal ini sesuai dengan tujuan test yang bermaksud menguji konsistensi item-item dalam instrumen penelitian.

Menghitung nilai reliabilitas digunakan rumus sebagai berikut :

$$
R=a=\frac{n}{n-1}\left(\frac{S-\Sigma S i}{S}\right)
$$

Sumber: Sugiyono (2013:276)

Keterangan :

$\mathrm{R}=$ Koefisien reliabilitas Alpha Cronbach

$\mathrm{n} \quad=$ Jumlah item

$\mathrm{S}=$ Varians skor keseluruhan

$\mathrm{Si} \quad=$ Varians masing-masing item.

Metode alpha cronbach $(\alpha)$ diukur berdasarkan skala alpha cronbach $(\alpha)$ dari 0,00 sampai 1,00. Jika skala itu dikelompokkan ke dalam lima kelas dengan range yang sama, ukuran kemantapan alpha dapat diinterprestasikan sebagai berikut :

1. Nilai alpha cronbach 0,00 s.d 0,20 berarti kurang reliabel.

2. Nilai alpha cronbach 0,21 s.d 0,40 berarti agak reliabel.

3. Nilai alpha cronbach 0,42 s.d 0,60 berarti cukup reliabel.

4. Nilai alpha cronbach 0,61 s.d 0,80 berarti reliabel.

5. Nilai alpha cronbach 0,81 s.d 1,00 berarti sangat reliabel.

Apabila nilai alpha 0,7 atau lebih maka dikatakan item tersebut memberikan tingkat reliabel yang cukup, sebaliknya apabila nilai alpha dibawah 0,7 maka dikatakan item tersebut kurang reliabel. Sebelum uji reliabilitas terlebih dahulu dicari korelasinya dengan rumus :

$$
r=\frac{n \Sigma A B-(\Sigma A)(\Sigma B)}{\sqrt{\left[n \Sigma A^{2}-(A)^{2}\right]\left[n \Sigma B^{2}-(\Sigma B)^{2}\right.}}
$$


Dimana :

$\mathrm{r}=$ Koefisien korelasi product moment

$\mathrm{A}=$ Variabel ganjil

$\mathrm{B}=$ Variabel genap

$\Sigma \mathrm{A}=$ Jumlah total skor belahan ganjil

$\Sigma \mathrm{B}=$ Jumlah total skor belahan genap

$\Sigma$ A2 $=$ Jumlah kuadran total skor belahan ganjil

$\Sigma$ B2 $=$ Jumlah kuadran total skor belahan genap

$\Sigma \mathrm{AB}=$ Jumlah perkalian skor jawaban belahan ganjil dan belahan genap

Koefisien korelasinya dimasukkan ke dalam rumus Spearman Brown. Adapun rumus Spearman Brown yaitu sebagai berikut :

$$
r=\frac{2 r_{b}}{1+r_{b}}
$$

Sumber: Sugiyono (2013:186)

Dimana :

$\mathrm{r}=$ Nilai reliabilitas

$\mathrm{rb}=$ Korelasi product moment antara belahan pertama (ganjil) dan belahan kedua (genap), batas reliabilitas minimal 0,7.

Setelah mendapatkan nilai reliabilitas instrumen (rb hitung), maka nilai tersebut dibandingkan dengan jumlah responden dan taraf nyata. Bila rhitung $\geq$ dari rtabel, maka instrumen tersebut dikatakan reliabel, sebaliknya jika rhitung $<$ dari rtabel maka instrumen tersebut dikatakan tidak reliabel.

\subsection{Populasi dan Sampel}

Menurut Sugiyono (2017:80) mendefinisikan populasi dalam penelitian kuantitatif, "Populasi adalah wilayah generalisasi yang terdiri atas: objek/subjek yang mempunyai kuantitas dan karakteristik tertentu yang ditetapkan oleh peneliti untuk dipelajari dan kemudian ditarik kesimpulannya."

Di dalam penelitian ini yang dimaksud populasi adalah customer yang telah melakukan transaksi atau pembelian pada Gramedia Asri Media Cabang Cinere Mall Depok berjumlah 30 orang. Dalam penelitian ini peneliti mengambil seluruh jumlah populasi karena subjeknya kurang dari 100, yaitu konsumen yang telah melakukan pembelian. 


\subsection{Skala Likert}

Menurut Sugiyono (2017:93) "Skala Likert digunakan untuk mengukur sikap, pendapat, dan persepsi seseorang atau sekelompok orang tentang fenomena sosial. Dalam penelitian, fenomena sosial ini telah ditetapkan secara spesifik oleh peneliti, yang selanjutnya disebut sebagai variabel penelitian."

Berikut adalah penilaian kuesioner menggunakan Skala Likert :

Tabel III.2

Skala Likert

\begin{tabular}{|l|l|}
\hline Pernyataan & $\begin{array}{l}\text { Pernyataan } \\
\text { Positif }\end{array}$ \\
\hline Sangat Setuju & 5 \\
\hline Setuju & 4 \\
\hline Netral & 3 \\
\hline Tidak Setuju & 2 \\
\hline Sangat Tidak Setuju & 1 \\
\hline \multicolumn{2}{|l|}{ Sumber : Sugiyono (2013:122) }
\end{tabular}

\subsection{Uji Koefisien Korelasi}

Menurut Siregar (2015:201), "Koefisien korelasi adalah bilangan yang menyatakan kekuatan antara dua variabel atau lebih atau juga dapat menentukan arah dari kedua variabel".

Nilai korelasi $(r)=(-1 \leq 0 \leq 1)$.

Untuk kekuatan hubungan, nilai koefisien korelasi berada diantara -1 dan 1 , sedangkan untuk arah dinyatakan dalam bentuk positif (+) dan negatif (-).

Misalnya:

a. Apabila $\mathrm{r}=-1$, artinya korelasi negatif sempurna, artinya terjadi hubungan tolak belakang antara variabel $\mathrm{X}$ dan variabel $\mathrm{Y}$, bila variabel $\mathrm{X}$ naik, maka variabel $\mathrm{Y}$ turun.

b. Apabila $\mathrm{r}=1$, artinya korelasi positif sempurna, artinya terjadi hubungan searah variabel X dan variabel $Y$, bila variabel X naik, maka variabel Y naik.

Koefisien korelasi dapat dikonsultasikan tabel pedoman pada tabel II.3 untuk memberikan interpretasi. 
Tabel Tingkat Korelasi dan Kekuatan Hubungan

\begin{tabular}{|l|l|}
\hline Interval Koefisien & Tingkat Hubungan \\
\hline $0,00-0,199$ & Sangat Lemah \\
\hline $0,20-0,399$ & Lemah \\
\hline $0,40-0,599$ & Cukup \\
\hline $0,60-0,799$ & Kuat \\
\hline $0,80-1,000$ & Sangat Kuat \\
\hline Sumber : Siregar (2015:202)
\end{tabular}

Menghitung nilai $r$

$$
\text { Rumus: } \quad r=\frac{n\left(\sum x y\right)-\left(\sum x \cdot \sum y\right)}{\sqrt{\left[n \sum x^{2}-\left(\sum x\right)^{2}\right]\left[n \sum y^{2}-\left(\sum y\right)^{2}\right]}}
$$

Sumber: Siregar (2015:203)

Keterangan

$\mathrm{n}:$ Jumlah data

$\mathrm{x}$ : Variabel bebas

y : Variabel terikat

\subsection{Koefisien Determinasi}

Menurut Siregar (2015:202) "Koefisien Determinasi adalah angka yang menyatakan atau digunakan untuk mengetahui kontribusi atau sumbangan yang diberikan oleh sebuah variabel atau lebih X (bebas) terhadap variabel Y terikat".

$$
\text { Rumus: } \mathrm{KD}=(\mathrm{R})^{2} \times 100 \%
$$

Sumber: Siregar (2015:202)

Keterangan :

KD : Koefisien Determinasi.

R : Koefisien Korelasi.

Koefisien determinasi ini digunakan untuk mengetahui presentasi pengaruh yang terjadi dari variabel bebas terhadap variabel tidak bebas dengan asumsi sebagai berikut: $0>\mathrm{R}^{2}>1$

a. Jika nilai $\mathrm{R}^{2}$ nya semakin mendekati angka 1 , maka model tersebut baik dan tingkat kedekatan antara variabel bebas dan terikat semakin dekat pula.

b. Jika semakin menjauhi angka 1, maka hubungan antar variabel bebas dengan variabel terikat tidak mendekati.

Nilai koefisien determinasi selalu positif, dengan nilai terkecil 0 (nol) dan terbesar adalah 1 (satu). Bila $\mathrm{R}^{2}=1$ berarti pengaruh variabel $\mathrm{X}$ (bebas) terhadap 
variabel Y (terikat) sebesar 100\%. Ini artinya tidak ada faktor lain yang mempengaruhi variabel Y.

\subsection{Persamaan Regresi}

Menurut Sugiyono (2007:236)“Antara korelasi dan regresi keduanya mempunyai hubungan yang sangat erat". Korelasi digunakan untuk menemukan arah dan kuatnya hubungan antara dua variabel atau lebih, sedangkan regresi digunakan untuk memprediksi nilai variabel dependen berdasarkan nilai variabel independen.

Pada umumnya setiap analisis regresi didahului dengan analisis korelasi, tetapi setiap analisis korelasi belum tentu dilanjutkan dengan regresi.

Persamaan umum regresi linier sederhana adalah :

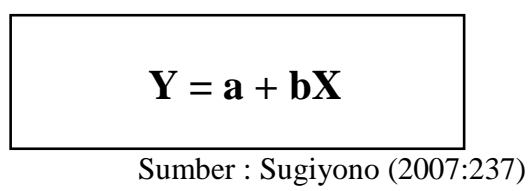

Dimana :

$\mathrm{Y}=$ Subyek / nilai dalam variabel dependent yang diprediksikan.

$\mathrm{a}=$ Harga $\mathrm{Y}$ bila $\mathrm{X}=0$ (harga Konstan)

$\mathrm{b}=$ Angka arah atau koefisien regresi, yang menunjukan angka peningkatan ataupun penurunan variabel dependen yang didasarkan pada variabel independent. Bila $\mathrm{b}(+)$ maka naik dan bila (-) maka terjadi penurunan.

$\mathrm{X}=$ Subyek pada variabel independent yang mempunyai nilai tertentu.

$$
\begin{aligned}
& \text { Nilai } \quad a \quad=\frac{(\Sigma Y)\left(\Sigma X^{2}\right)-(\Sigma X)(\Sigma X Y)}{n \Sigma X^{2}-\left(\Sigma X^{2}\right)} \\
& \text { Nilai } b=\frac{n \Sigma X Y-(\Sigma X)(\Sigma Y)}{n \Sigma X^{2}-\left(\Sigma X^{2}\right)} \\
& \text { Sumber :Sugiyono (2007:238) }
\end{aligned}
$$

\section{HASIL PENELITIAN DAN PEMBAHASAN}

\subsection{Uji Validitas}

Uji ini dalam program SPSS 23 dapat dilihat pada kolom corrected item total correlation yang merupakan nilai $r$ hitung untuk masing-masing pertanyaan. Apabila nilai $r$ lebih besar dari $r$ tabel, maka butir-butir pertanyaan tersebut dapat dinyatakan valid. Untuk menguji validitas dan reliabilitas instrumen, penulis menggunakan analisis SPSS 23. Berdasarkan hasil pengolahan data menggunakan program SPSS 23 diperoleh hasil uji validitas dan reliabilitas kuesioner kedua variabel seperti berikut. 


\section{Tabel IV.1}

Hasil Uji Validitas Variabel Brand Awareness (X)

Item-Total Statistics

\begin{tabular}{|l|l|l|l|l|}
\hline & $\begin{array}{l}\text { Scale Mean if } \\
\text { Item Deleted }\end{array}$ & $\begin{array}{l}\text { Scale Variance if } \\
\text { Item Deleted }\end{array}$ & $\begin{array}{l}\text { Corrected Item-Total } \\
\text { Correlation }\end{array}$ & $\begin{array}{l}\text { Cronbach's Alpha if } \\
\text { Item Deleted }\end{array}$ \\
\hline X1 & 29,4667 & 16,878 &, 659 &, 854 \\
X2 & 29,2000 & 19,821 &, 631 &, 852 \\
X3 & 29,4667 & 20,189 &, 498 &, 866 \\
X4 & 29,1333 & 19,637 &, 677 &, 847 \\
X5 & 29,2667 & 19,926 &, 709 &, 846 \\
X6 & 28,7333 & 21,444 &, 579 &, 860 \\
X7 & 29,1000 & 17,817 &, 734 &, 839 \\
X8 & 28,9667 & 18,930 &, 618 &, 853 \\
\hline
\end{tabular}

Sumber: Hasil Olah Data SPPS Versi 23

Berdasarkan tabel di atas, hasil olah data SPSS versi 23 untuk validitas instrumen Brand Awareness (X) peneliti mendapatkan hasil valid disetiap pernyataan yang peneliti ajukan kepada responden. Dalam penulisan ini peneliti memiliki sampel sebanyak 30 responden. Sehingga, berdasarkan distribusi $r$ tabel dengan $\mathrm{df}=\mathrm{n}-2$, maka df $=30-2=28$ dan taraf kesalahan $1 \%$, maka penentuan batas minimal validitas pertanyaan sebesar 0,3061 .

Tabel IV.2

Hasil Uji Validitas Variabel Keputusan Pembelian (Y)

Item-Total Statistics

\begin{tabular}{|l|l|l|l|l|}
\hline & $\begin{array}{l}\text { Scale Mean if } \\
\text { Item Deleted }\end{array}$ & $\begin{array}{l}\text { Scale Variance } \\
\text { if Item Deleted }\end{array}$ & $\begin{array}{l}\text { Corrected Item- } \\
\text { Total Correlation }\end{array}$ & $\begin{array}{l}\text { Alpha if Item } \\
\text { Deleted }\end{array}$ \\
\hline Y1 & 38,5667 & 18,254 &, 750 &, 830 \\
Y2 & 38,3667 & 20,723 &, 598 &, 845 \\
Y3 & 38,3333 & 21,609 &, 462 &, 857 \\
Y4 & 38,4667 & 20,671 &, 634 &, 842 \\
Y5 & 38,4333 & 22,944 &, 439 &, 857 \\
Y6 & 38,5333 & 21,499 &, 492 &, 854 \\
Y7 & 38,4667 & 22,533 &, 473 &, 855 \\
Y8 & 38,3667 & 23,206 &, 423 &, 858 \\
Y9 & 38,5333 & 18,740 &, 823 &, 846 \\
Y10 & 38,2333 & 21,495 &, 597 & \\
\hline
\end{tabular}

Sumber: Hasil Olah Data SPSS Versi 23 
Terkait dengan tabel di atas, hasil olah data SPSS versi 23 untuk validitas instrumen Keputusan Pembelian (Y) peneliti mendapatkan hasil valid dalam tiap pernyataan yang peneliti ajukan kepada responden yang berjumlah 30 responden. Berdasarkan distribusi $\mathrm{r}$ tabel dengan $\mathrm{df}=\mathrm{n}-2$, maka $\mathrm{df}=30-2=28$ dan taraf kesalahan $1 \%$ maka penentuan batas minimal validitas pertanyaan sebesar 0,3061 .

\subsection{Uji Reliabilitas}

Uji Reliabilitas terhadap variabel X dan Y sebagai berikut :

Tabel IV.3

Hasil Uji Reliabilitas Variabel Brand Awareness (X)

Reliability Statistics

\begin{tabular}{|l|l|}
\hline Cronbach's Alpha & N of Items \\
\hline, 868 & 8 \\
\hline
\end{tabular}

Sumber: Hasil Olah Data SPSS Versi 23

Tabel di atas menunjukkan angka Cronbach's Alpha sebesar 0,868 yang berarti instrumen penelitian untuk variabel Brand Awareness (X) adalah sangat reliabel. Berdasarkan landasan teori yang penulis sampaikan pada bab dua bahwa 0,81 adalah kuat, karena nilai 0,868 maka hasilnya sangat reliabel dan dikatakan reliabel. Jumlah item $(\mathrm{N})$ adalah 8 item pertanyaan. Pada uji reliabilitas dalam penelitian ini menggunakan SPSS 23 dengan model Alpha.

Tabel Hasil Uji Reliabilitas Variabel Keputusan Pembelian (Y)

Reliability Statistics

\begin{tabular}{|l|l|}
\hline Cronbach's Alpha & N of Items \\
\hline, 861 & 10 \\
\hline
\end{tabular}

Sumber: Hasil Olah Data SPSS Versi 23

Tabel di atas menunjukkan angka Cronbach's Alpha sebesar 0,861 yang berarti instrumen penelitian untuk variabel Keputusan Pembelian (Y) adalah sangat reliabel. Berdasarkan landasan teori yang penulis sampaikan pada bab dua bahwa 0,81 adalah kuat, karena nilai 0,861 maka hasilnya sangat reliabel dan dikatakan reliabel. Jumlah item $(\mathrm{N})$ adalah 10 item pertanyaan. Pada uji reliabilitas dalam penelitian ini menggunakan SPSS 23 dengan model Alpha.

\subsection{Data Hasil Kuesioner Variabel Brand Awareness (X)}




\section{Unware of brand (tidak menyadari merek)}

Tabel Mengetahui Gramedia merupakan anak Perusahaan Kompas Gramedia

\begin{tabular}{|l|l|l|l|}
\hline No & Tingkat Pernyataan & Frekuensi & Persentase \\
\hline $\mathbf{1}$ & Sangat Setuju & 11 & $37 \%$ \\
\hline $\mathbf{2}$ & Setuju & 11 & $37 \%$ \\
\hline $\mathbf{3}$ & Netral & 2 & $7 \%$ \\
\hline $\mathbf{4}$ & Tidak Setuju & 5 & $17 \%$ \\
\hline $\mathbf{5}$ & Sangat Tidak Setuju & 1 & $3 \%$ \\
\hline Jumlah & 30 & $100 \%$ \\
\hline
\end{tabular}

Sumber: Data Primer yang diolah, 2019

Berdasarkan tabel diatas, dapat diperoleh informasi bahwa konsumen PT Gramedia Asri Media Cabang Cinere Mall Depok memberikan jawaban Sangat Setuju sebanyak 11 orang dengan persentase 37\%, Setuju sebanyak 11 orang dengan persentase $37 \%$, Netral sebanyak 2 orang dengan persentase $7 \%$, Tidak Setuju sebanyak 5 orang dengan persentase $17 \%$, dan Sangat Tidak Setuju sebanyak 1 orang dengan persentase $3 \%$.

Tabel "Sering melihat Logo G sebagai lambing Gramedia"

\begin{tabular}{|l|l|l|l|}
\hline NO & TINGKAT PERNYATAAN & FREKUENSI & PERSENTASE \\
\hline $\mathbf{1}$ & Sangat Setuju & 10 & $33 \%$ \\
\hline $\mathbf{2}$ & Setuju & 15 & $50 \%$ \\
\hline $\mathbf{3}$ & Netral & 4 & $13 \%$ \\
\hline $\mathbf{4}$ & Tidak Setuju & 1 & $3 \%$ \\
\hline $\mathbf{5}$ & Sangat Tidak Setuju & 0 & $0 \%$ \\
\hline JUMLAH & 30 & $100 \%$ \\
\hline
\end{tabular}

Sumber: Data Primer yang diolah, 2019

Berdasarkan tabel diatas, dapat diperoleh informasi bahwa konsumen PT Gramedia Asri Media Cabang Cinere Mall Depok memberikan jawaban Sangat Setuju sebanyak 10 orang dengan persentase 33\%, Setuju sebanyak 15 orang dengan persentase $50 \%$, Netral sebanyak 4 orang dengan persentase 13\%, Tidak Setuju sebanyak 1 orang dengan persentase 3\%, dan Sangat Tidak Setuju sebanyak 0 orang dengan persentase $0 \%$.

\section{Brand recognition (pengenalan merek)}


Tabel "Pengenalan merek melalui Logo"

\begin{tabular}{|l|l|l|l|}
\hline No & Tingkat Pernyataan & Frekuensi & Persentase \\
\hline $\mathbf{1}$ & Sangat Setuju & 6 & $20 \%$ \\
\hline $\mathbf{2}$ & Setuju & 17 & $57 \%$ \\
\hline $\mathbf{3}$ & Netral & 4 & $13 \%$ \\
\hline $\mathbf{4}$ & Tidak Setuju & 3 & $10 \%$ \\
\hline $\mathbf{5}$ & Sangat Tidak Setuju & 0 & $0 \%$ \\
\hline Jumlah & 30 & $100 \%$ \\
\hline
\end{tabular}

Berdasarkan tabel diatas, dapat diperoleh informasi bahwa konsumen PT Gramedia Asri Media Cabang Cinere Mall Depok memberikan jawaban Sangat Setuju sebanyak 6 orang dengan persentase 20\%, Setuju sebanyak 17 orang dengan persentase $57 \%$, Netral sebanyak 4 orang dengan persentase 10\%, Tidak Setuju sebanyak 3 orang dengan persentase $10 \%$, dan Sangat Tidak Setuju sebanyak 0 orang dengan persentase $0 \%$.

Tabel "Mengingat merek dengan bantuan promosi dan iklan"

\begin{tabular}{|l|l|l|l|}
\hline NO & TINGKAT PERNYATAAN & FREKUENSI & Persentase \\
\hline $\mathbf{1}$ & Sangat Setuju & 10 & $33 \%$ \\
\hline $\mathbf{2}$ & Setuju & 18 & $60 \%$ \\
\hline $\mathbf{3}$ & Netral & 0 & $0 \%$ \\
\hline $\mathbf{4}$ & Tidak Setuju & 2 & $7 \%$ \\
\hline $\mathbf{5}$ & Sangat Tidak Setuju & 0 & $0 \%$ \\
\hline Jumlah & 30 & $100 \%$ \\
\hline
\end{tabular}

Sumber: Data Primer yang diolah, 2019

Berdasarkan tabel diatas, dapat diperoleh informasi bahwa konsumen PT Gramedia Asri Media Cabang Cinere Mall Depok memberikan jawaban Sangat Setuju sebanyak 10 orang dengan persentase 33\%, Setuju sebanyak 18 orang dengan persentase $60 \%$, Netral sebanyak 0 orang dengan persentase $0 \%$, Tidak Setuju sebanyak 2 orang dengan persentase 7\%, dan Sangat Tidak Setuju sebanyak 0 orang dengan persentase $0 \%$. 


\section{Brand Recall (peningkatan kembali terhadap merek)}

Tabel "Mengingat merek tanpa melihat adanya suatu promosi atau iklan"

\begin{tabular}{|l|l|l|l|}
\hline No & Tingkat Pernyataan & Frekuensi & Persentase \\
\hline $\mathbf{1}$ & Sangat Setuju & 6 & $20 \%$ \\
\hline $\mathbf{2}$ & Setuju & 22 & $73 \%$ \\
\hline $\mathbf{3}$ & Netral & 0 & $0 \%$ \\
\hline $\mathbf{4}$ & Tidak Setuju & 2 & $7 \%$ \\
\hline $\mathbf{5}$ & Sangat Tidak Setuju & 0 & $0 \%$ \\
\hline Jumlah & 30 & $100 \%$ \\
\hline
\end{tabular}

Berdasarkan tabel diatas, dapat diperoleh informasi bahwa konsumen PT Gramedia Asri Media Cabang Cinere Mall Depok memberikan jawaban Sangat Setuju sebanyak 6 orang dengan persentase 20\%, Setuju sebanyak 22 orang dengan persentase $73 \%$, Netral sebanyak 0 orang dengan persentase $0 \%$, Tidak Setuju sebanyak 2 orang dengan persentase 7\%, dan Sangat Tidak Setuju sebanyak 0 orang dengan persentase $0 \%$.

Tabel Hanya Gramedia yang akan dikunjungi saat ingin berbelanja buku-buku bacaan dan perlengkapan sekolah serta kantor

\begin{tabular}{|l|l|l|l|}
\hline No & Tingkat Pernyataan & Frekuensi & Persentase \\
\hline $\mathbf{1}$ & Sangat Setuju & 19 & $63 \%$ \\
\hline $\mathbf{2}$ & Setuju & 10 & $33 \%$ \\
\hline $\mathbf{3}$ & Netral & 1 & $3 \%$ \\
\hline $\mathbf{4}$ & Tidak Setuju & 0 & $0 \%$ \\
\hline $\mathbf{5}$ & Sangat Tidak Setuju & 0 & $0 \%$ \\
\hline Jumlah & 30 & $100 \%$ \\
\hline
\end{tabular}

Sumber: Data Primer yang diolah, 2019

Berdasarkan tabel diatas, dapat diperoleh informasi bahwa konsumen PT Gramedia Asri Media Cabang Cinere Mall Depok memberikan jawaban Sangat Setuju sebanyak 19 orang dengan persentase 63\%, Setuju sebanyak 10 orang dengan persentase $33 \%$, Netral sebanyak 1 orang dengan persentase 3\%, Tidak Setuju sebanyak 0 orang dengan persentase $0 \%$, dan Sangat Tidak Setuju sebanyak 0 orang dengan persentase $0 \%$.

\section{Top of mind (puncak pikiran)}


Tabel "Merek Gramedia telah tertanam dibenak konsumen"

\begin{tabular}{|l|l|l|l|}
\hline No & Tingkat Pernyataan & Frekuensi & Persentase \\
\hline $\mathbf{1}$ & Sangat Setuju & 14 & $47 \%$ \\
\hline $\mathbf{2}$ & Setuju & 12 & $40 \%$ \\
\hline $\mathbf{3}$ & Netral & 2 & $7 \%$ \\
\hline $\mathbf{4}$ & Tidak Setuju & 1 & $3 \%$ \\
\hline $\mathbf{5}$ & Sangat Tidak Setuju & 1 & $3 \%$ \\
\hline Jumlah & 30 & $100 \%$ \\
\hline
\end{tabular}

Sumber: Data Primer yang diolah, 2019

Berdasarkan tabel diatas, dapat diperoleh informasi bahwa konsumen PT Gramedia Asri Media Cabang Cinere Mall Depok memberikan jawaban Sangat Setuju sebanyak 14 orang dengan persentase 47\%, Setuju sebanyak 12 orang dengan persentase $40 \%$, Netral sebanyak 2 orang dengan persentase 7\%, Tidak Setuju sebanyak 1 orang dengan persentase 3\%, dan Sangat Tidak Setuju sebanyak 1 orang dengan persentase $3 \%$.

Tabel "Sering membeli produk di Gramedia"

\begin{tabular}{|l|l|l|l|}
\hline No & Tingkat Pernyataan & Frekuensi & Persentase \\
\hline $\mathbf{1}$ & Sangat Setuju & 17 & $57 \%$ \\
\hline $\mathbf{2}$ & Setuju & 10 & $33 \%$ \\
\hline $\mathbf{3}$ & Netral & 0 & $0 \%$ \\
\hline $\mathbf{4}$ & Tidak Setuju & 3 & $10 \%$ \\
\hline $\mathbf{5}$ & Sangat Tidak Setuju & 0 & $0 \%$ \\
\hline Jumlah & 30 & $100 \%$ \\
\hline
\end{tabular}

Sumber: Data Primer yang diolah, 2019

Berdasarkan tabel diatas, dapat diperoleh informasi bahwa konsumen PT Gramedia Asri Media Cabang Cinere Mall Depok memberikan jawaban Sangat Setuju sebanyak 19 orang dengan persentase 63\%, Setuju sebanyak 10 orang dengan persentase 33\%, Netral sebanyak 1 orang dengan persentase 3\%, Tidak Setuju

\section{Data Hasil Kuesioner Variabel Keputusan Pembelian (Y)}

\section{A. Pengenalan Masalah}

Tabel "Kebutuhan akhir-akhir ini ialah produk-produk Gramedia"

\begin{tabular}{|l|l|l|l|}
\hline No & Tingkat Pernyataan & Frekuensi & Persentase \\
\hline $\mathbf{1}$ & Sangat Setuju & 13 & $43 \%$ \\
\hline $\mathbf{2}$ & Setuju & 12 & $40 \%$ \\
\hline 3 & Netral & 1 & $3 \%$ \\
\hline
\end{tabular}




\begin{tabular}{|l|l|l|l|}
$\mathbf{4}$ & Tidak Setuju & 4 & $13 \%$ \\
\hline $\mathbf{5}$ & Sangat Tidak Setuju & 0 & $0 \%$ \\
\hline Jumlah & 30 & $100 \%$ \\
\hline
\end{tabular}

Berdasarkan tabel diatas, dapat diperoleh informasi bahwa konsumen PT Gramedia Asri Media Cabang Cinere Mall Depok memberikan jawaban Sangat Setuju sebanyak 13 orang dengan persentase 43\%, Setuju sebanyak 12 orang dengan persentase $40 \%$, Netral sebanyak 1 orang dengan persentase 3\%, Tidak Setuju sebanyak 4 orang dengan persentase 13\%, dan Sangat Tidak Setuju sebanyak 0 orang dengan persentase $0 \%$.

Tabel "Membutuhkan tempat berbelanja dengan tempat yang stategis dan pelayanan yang baik"

\begin{tabular}{|l|l|l|l|}
\hline No & Tingkat Pernyataan & Frekuensi & Persentase \\
\hline $\mathbf{1}$ & Sangat Setuju & 14 & $47 \%$ \\
\hline $\mathbf{2}$ & Setuju & 14 & $47 \%$ \\
\hline 3 & Netral & 0 & $0 \%$ \\
\hline $\mathbf{4}$ & Tidak Setuju & 2 & $7 \%$ \\
\hline $\mathbf{5}$ & Sangat Tidak Setuju & 0 & $0 \%$ \\
\hline Jumlah & 30 & $100 \%$ \\
\hline
\end{tabular}

Sumber: Data Primer yang diolah, 2019

Berdasarkan tabel diatas, dapat diperoleh informasi bahwa konsumen PT Gramedia Asri Media Cabang Cinere Mall Depok memberikan jawaban Sangat Setuju sebanyak 14 orang dengan persentase 47\%, Setuju sebanyak 14 orang dengan persentase $47 \%$, Netral sebanyak 0 orang dengan persentase $0 \%$, Tidak Setuju sebanyak 2 orang dengan persentase 7\%, dan Sangat Tidak Setuju sebanyak 0 orang dengan persentase $0 \%$.

\section{B. Pencarian Informasi}

Tabel "Mencari informasi sebelum berkunjung ke Gramedia"

\begin{tabular}{|l|l|l|l|}
\hline No & Tingkat Pernyataan & Frekuensi & Persentase \\
\hline $\mathbf{1}$ & Sangat Setuju & 15 & $50 \%$ \\
\hline $\mathbf{2}$ & Setuju & 13 & $43 \%$ \\
\hline $\mathbf{3}$ & Netral & 0 & $0 \%$ \\
\hline $\mathbf{4}$ & Tidak Setuju & 2 & $7 \%$ \\
\hline $\mathbf{5}$ & SangatTidak Setuju & 0 & $0 \%$ \\
\hline Jumlah & 30 & $100 \%$ \\
\hline
\end{tabular}


Sumber: Data Primer yang diolah, 2019

Berdasarkan tabel diatas, dapat diperoleh informasi bahwa konsumen PT Gramedia Asri Media Cabang Cinere Mall Depok memberikan jawaban Sangat Setuju sebanyak 15 orang dengan persentase 50\%, Setuju sebanyak 13 orang dengan persentase $43 \%$, Netral sebanyak 0 orang dengan persentase $0 \%$, Tidak Setuju sebanyak 2 orang dengan persentase 7\%, dan Sangat Tidak Setuju sebanyak 0 orang dengan persentase $0 \%$.

Tabel "Mengetahui Gramedia dari teman,keluarga, dan media sosial"

\begin{tabular}{|l|l|l|l|}
\hline No & Tingkat Pernyataan & Frekuensi & Persentase \\
\hline $\mathbf{1}$ & Sangat Setuju & 11 & $37 \%$ \\
\hline $\mathbf{2}$ & Setuju & 17 & $57 \%$ \\
\hline 3 & Netral & 0 & $0 \%$ \\
\hline $\mathbf{4}$ & Tidak Setuju & 2 & $7 \%$ \\
\hline $\mathbf{5}$ & Sangat Tidak Setuju & 0 & $0 \%$ \\
\hline Jumlah & 30 & $100 \%$ \\
\hline
\end{tabular}

Sumber: Data Primer yang diolah, 2019

Berdasarkan tabel diatas, dapat diperoleh informasi bahwa konsumen PT Gramedia Asri Media Cabang Cinere Mall Depok memberikan jawaban Sangat Setuju sebanyak 11 orang dengan persentase 37\%, Setuju sebanyak 17 orang dengan persentase $57 \%$, Netral sebanyak 0 orang dengan persentase $0 \%$, Tidak Setuju sebanyak 2 orang dengan persentase 7\%, dan Sangat Tidak Setuju sebanyak 0 orang dengan persentase $0 \%$.

\section{Evaluasi Alternatif}

Tabel "Memilih merek Gramedia karena kualitas produk yang baik"

\begin{tabular}{|l|l|l|l|}
\hline No & Tingkat Pernyataan & Frekuensi & Persentase \\
\hline $\mathbf{1}$ & Sangat Setuju & 10 & $33 \%$ \\
\hline $\mathbf{2}$ & Setuju & 18 & $60 \%$ \\
\hline 3 & Netral & 2 & $7 \%$ \\
\hline $\mathbf{4}$ & Tidak Setuju & 0 & $0 \%$ \\
\hline $\mathbf{5}$ & Sangat Tidak Setuju & 0 & $0 \%$ \\
\hline Jumlah & 30 & $100 \%$ \\
\hline
\end{tabular}

Berdasarkan tabel diatas, dapat diperoleh informasi bahwa konsumen PT Gramedia Asri Media Cabang Cinere Mall Depok memberikan jawaban Sangat Setuju sebanyak 10 orang dengan persentase 33\%, Setuju sebanyak 18 orang dengan 
persentase $60 \%$, Netral sebanyak 2 orang dengan persentase 7\%, Tidak Setuju sebanyak 0 orang dengan persentase $0 \%$, dan Sangat Tidak Setuju sebanyak 0 orang dengan persentase $0 \%$.

Tabel "Pelayanan Gramedia cepat dan ramah"

\begin{tabular}{|c|c|c|c|}
\hline No & Tingkat Pernyataan & Frekuensi & Persentase \\
\hline $\mathbf{1}$ & Sangat Setuju & 10 & $33 \%$ \\
\hline 2 & Setuju & 17 & $57 \%$ \\
\hline 3 & Netral & 1 & $3 \%$ \\
\hline 4 & Tidak Setuju & 2 & $7 \%$ \\
\hline 5 & Sangat Tidak Setuju & 0 & $0 \%$ \\
\hline \multicolumn{2}{|c|}{ Jumlah } & 30 & $100 \%$ \\
\hline
\end{tabular}

Berdasarkan tabel diatas, dapat diperoleh informasi bahwa konsumen PT Gramedia Asri Media Cabang Cinere Mall Depok memberikan jawaban Sangat Setuju sebanyak 10 orang dengan persentase 33\%, Setuju sebanyak 17 orang dengan persentase $57 \%$, Netral sebanyak 1 orang dengan persentase 3\%, Tidak Setuju sebanyak 2 orang dengan persentase 7\%, dan Sangat Tidak Setuju sebanyak 0 orang dengan persentase $0 \%$.

\section{Keputusan pembelian}

Tabel "Memutuskan melakukann pembelian setelah penjabaran suasana secara visual atau pengalaman secara langsung"

\begin{tabular}{|l|l|l|l|}
\hline No & Tingkat Pernyataan & Frekuensi & Persentase \\
\hline $\mathbf{1}$ & Sangat Setuju & 9 & $30 \%$ \\
\hline $\mathbf{2}$ & Setuju & 20 & $67 \%$ \\
\hline 3 & Netral & 0 & $0 \%$ \\
\hline $\mathbf{4}$ & Tidak Setuju & 1 & $3 \%$ \\
\hline $\mathbf{5}$ & Sangat Tidak Setuju & 0 & $0 \%$ \\
\hline Jumlah & 30 & $100 \%$ \\
\hline \multicolumn{2}{|c|}{ Sumber: Data Primer yang diolah, 2019 }
\end{tabular}

Berdasarkan tabel diatas, dapat diperoleh informasi bahwa konsumen PT Gramedia Asri Media Cabang Cinere Mall Depok memberikan jawaban Sangat Setuju sebanyak 9 orang dengan persentase $30 \%$, Setuju sebanyak 20 orang dengan persentase $67 \%$, Netral sebanyak 0 orang dengan persentase 0\%, Tidak Setuju sebanyak 1 orang dengan persentase 3\%, dan Sangat Tidak Setuju sebanyak 0 orang dengan persentase $0 \%$. 
Tabel IV.20

"Memilih karena ingin mengetahui varian jenis"

\begin{tabular}{|l|l|l|l|}
\hline No & Tingkat Pernyataan & Frekuensi & Persentase \\
\hline $\mathbf{1}$ & Sangat Setuju & 11 & $37 \%$ \\
\hline $\mathbf{2}$ & Setuju & 18 & $60 \%$ \\
\hline 3 & Netral & 1 & $3 \%$ \\
\hline $\mathbf{4}$ & Tidak Setuju & 0 & $0 \%$ \\
\hline $\mathbf{5}$ & Sangat Tidak Setuju & 0 & $0 \%$ \\
\hline Jumlah & 30 & $100 \%$ \\
\hline
\end{tabular}

Sumber: Data Primer yang diolah, 2019

Berdasarkan tabel diatas, dapat diperoleh informasi bahwa konsumen PT Gramedia Asri Media Cabang Cinere Mall Depok memberikan jawaban Sangat Setuju sebanyak 11 orang dengan persentase 37\%, Setuju sebanyak 18 orang dengan persentase $60 \%$, Netral sebanyak 1 orang dengan persentase 3\%, Tidak Setuju sebanyak 0 orang dengan persentase $0 \%$, dan Sangat Tidak Setuju sebanyak 0 orang dengan persentase $0 \%$.

\section{E. Perilaku setelah pembelian}

Tabel "Akan kembali berkunjung"

\begin{tabular}{|l|l|l|l|}
\hline No & Tingkat Pernyataan & Frekuensi & Persentase \\
\hline $\mathbf{1}$ & Sangat Setuju & 11 & $37 \%$ \\
\hline $\mathbf{2}$ & Setuju & 16 & $53 \%$ \\
\hline 3 & Netral & 0 & $0 \%$ \\
\hline $\mathbf{4}$ & Tidak Setuju & 3 & $10 \%$ \\
\hline $\mathbf{5}$ & Sangat Tidak Setuju & 0 & $0 \%$ \\
\hline Jumlah & 30 & $100 \%$ \\
\hline \multicolumn{2}{|c|}{ Sumber: Data Primer yang diolah, 2019} \\
\hline
\end{tabular}

Berdasarkan tabel diatas, dapat diperoleh informasi bahwa konsumen PT Gramedia Asri Media Cabang Cinere Mall Depok memberikan jawaban Sangat Setuju sebanyak 11 orang dengan persentase 37\%, Setuju sebanyak 16 orang dengan persentase $53 \%$, Netral sebanyak 0 orang dengan persentase $0 \%$, Tidak Setuju sebanyak 3 orang dengan persentase $10 \%$, dan Sangat Tidak Setuju sebanyak 0 orang dengan persentase $0 \%$. 
Tabel Akan merekomendasikan kepada orang terdekat

\begin{tabular}{|l|l|l|l|}
\hline No & Tingkat Pernyataan & Frekuensi & Persentase \\
\hline $\mathbf{1}$ & Sangat Setuju & 16 & $53 \%$ \\
\hline $\mathbf{2}$ & Setuju & 13 & $43 \%$ \\
\hline 3 & Netral & 0 & $0 \%$ \\
\hline $\mathbf{4}$ & Tidak Setuju & 1 & $3 \%$ \\
\hline $\mathbf{5}$ & Sangat Tidak Setuju & 0 & $0 \%$ \\
\hline Jumlah & 30 & $100 \%$ \\
\hline \multicolumn{4}{|c|}{ Sumber: Data Primer yang diolah, 2019 }
\end{tabular}

Berdasarkan tabel diatas, dapat diperoleh informasi bahwa konsumen PT Gramedia Asri Media Cabang Cinere Mall Depok memberikan jawaban Sangat Setuju sebanyak 16 orang dengan persentase 53\%, Setuju sebanyak 13 orang dengan persentase $43 \%$, Netral sebanyak 0 orang dengan persentase 0\%, Tidak Setuju sebanyak 1 orang dengan persentase 3\%, dan Sangat Tidak Setuju sebanyak 0 orang dengan persentase $0 \%$.

\section{Uji Koefisien Korelasi}

Setelah diperoleh data primer selanjutnya dilakukan analisa statistik dengan metode regresi linier, pertama mencari koefisien korelasi terlebih dahulu. Untuk mengukur tingkat hubungan antara variabel $\mathrm{X}$ (brand awareness) dan variabel $\mathrm{Y}$ (keputusan pembelian).

Adapun pengujian dengan SPSS 23 hasilnya adalah sebagai berikut :

Table Hasil Koefisien Korelasi

\section{Correlations}

\begin{tabular}{llll} 
& & $\begin{array}{l}\text { Brand } \\
\text { Awareness }\end{array}$ & $\begin{array}{l}\text { Keputusan } \\
\text { Pembelian }\end{array}$ \\
\hline Brand & Pearson Correlation & 1 &, $789^{* * *}$ \\
Awareness & Sig. (2-tailed) & &, 000 \\
& $\mathrm{~N}$ & 30 & 30 \\
Keputusan & Pearson Correlation &, $789^{* *}$ & 1 \\
Pembelian & Sig. (2-tailed) &, 000 & \\
& $\mathrm{~N}$ & 30 & 30 \\
\hline
\end{tabular}

**. Correlation is significant at the 0.01 level (2-tailed).

Sumber: Hasil olah data SPSS versi 23 
Dari hasil perhitungan Koefisien Korelasi product moment dan berdasarkan tabel Koefisien Korelasi di atas dapat diketahui bahwa terdapat hubungan (korelasi) antara brand awareness dengan keputusan pembelian sebesar 0,789. Untuk dapat memberi interpretasi terhadap kuatnya hubungan itu, maka dapat digunakan pedoman seperti yang tertera pada Tabel di atas. berdasarkan tabel tersebut maka koefisien korelasi yang ditemukan sebesar 0,789 termasuk pada kategori "Kuat" dan searah karena bernilai positif dan mendekati angka 1.

Pengujian korelasi menggunakan pedoman interpretasi koefisien korelasinya adalah sebagai berikut :

Tabel Interval Nilai Koefisien Nilai Korelasi dan Kekuatan Hubungan

\begin{tabular}{|c|l|}
\hline Interval Nilai & Tingkat Hubungan \\
\hline $0,00-0,19$ & Sangat Rendah \\
$0,20-0,39$ & Rendah \\
$0,40-0,69$ & Sedang \\
$0,70-0,89$ & Kuat \\
$0,90-0,99$ & Sangat Kuat \\
1,00 & Sempurna \\
\hline Sumber : Siregar $(2015: 202)$ & \\
\hline
\end{tabular}

\section{Koefisien Determinasi}

Untuk mengetahui pengaruh brand awareness terhadap keputusan pembelian pada PT Gramedia Asri Media Cabang Cinere Mall Depok, maka digunakan uji koefisien determinasi. Perhitungan Koefisien Determinasi, yaitu:

Table Hasil Koefisien Determinasi

\section{Model Summary}

\begin{tabular}{|l|l|l|l|l|l|}
\hline $\begin{array}{l}\text { Mode } \\
1\end{array}$ & $\mathrm{R}$ & R Square & $\begin{array}{l}\text { Adjusted } \\
\text { Square }\end{array}$ & $\begin{array}{l}\text { Std. Error of the } \\
\text { Estimate }\end{array}$ \\
\hline 1 &, $789^{\mathrm{a}}$ &, 623 &, 609 & 3,17036 \\
\hline
\end{tabular}

a. Predictors: (Constant), Brand Awareness

Sumber: Hasil olah data SPSS versi 23

Pada tabel di atas dapat dilihat bahwa nilai Adjusted R2 adalah sebesar 0,609. Hal ini dapat diartikan bahwa variabel independent (brand awareness) dapat menjelaskan variabel dependent (keputusan pembelian) sebesar 60,9\%, sedangkan sisanya 39,09\% diterangkan oleh faktor lain yang tidak diteliti. 


\section{Uji Persamaan Regresi}

Selanjutnya dilanjutkan dengan analisis regresi linear digunakan dalam penelitian ini dengan tujuan untuk mengetahui ada tidaknya pengaruh variabel independent terhadap variabel dependent.

Ringkasan hasil pengolahan data dengan menggunakan program SPSS versi 23 adalah sebagai berikut:

Table Hasil Uji Regresi

\section{Coefficients $^{\mathrm{a}}$}

\begin{tabular}{|l|l|l|l|l|l|}
\hline \multirow{2}{*}{ Model } & \multicolumn{2}{|l|}{$\begin{array}{l}\text { Unstandardized } \\
\text { Coefficients }\end{array}$} & $\begin{array}{l}\text { Standardized } \\
\text { Coefficients }\end{array}$ & & \multirow{2}{*}{ Sig. } \\
\cline { 2 - 5 } & B & Std. Error & Beta & $\mathrm{t}$ &, 000 \\
\hline (Constant) & 15,89 & 3,984 & & 3,988 &, 000 \\
\hline
\end{tabular}

a. Dependent Variable: Keputusan Pembelian

Sumber : Hasil olah data SPSS versi 23

Hasil analisis tersebut dapat disusun model persamaan regresi linier sederhana sebagai berikut:

$$
Y=15,891+\mathbf{0 , 8 0 4 X}
$$

Persamaan ini dapat diinterpretasikan sebagai berikut:

Konstanta (a): $\quad$ 15,891, nilai konstanta bernilai positif jika skor variabel brand awareness berarti skor keputusan pembelian akan semakin meningkat.

Koefisien (b): $\quad 0,804$, koefisien variabel keputusan pembelian bernilai positif artinya pengaruh brand awareness terhadap keputusan pemebelian PT Gramedia Asri Media Cabang Cinere Mall Depok adalah bersifat positif. Jika skor brand awareness meningkat, maka keputusan pembelian akan semakin meningkat.

\section{SIMPULAN DAN SARAN}

1. Berdasarkan hasil uji koefisien kolerasi antara variabel brand awareness (X) terhadap variabel keputusan pembelian (Y) PT Gramedia Asri Media Cabang Cinere Mall Depok dapat diketahui bahwa terdapat hubungan (korelasi) antara brand 
awareness dengan keputusan pembelian sebesar 0,789 termasuk pada kategori "Kuat" dan searah karena bernilai positif dan mendekati angka 1.

2. Berdasarkan hasil uji koefisien determinasi antara variabel brand awareness (X) terhadap variabel keputusan pembelian (Y) PT Gramedia Asri Media Cabang Cinere Mall Depok didapatkan nilai Adjusted R2 adalah sebesar 0,609. Hal ini dapat diartikan bahwa variabel independent (brand awareness) dapat menjelaskan variabel dependent (keputusan pembelian) sebesar 60,9\%, sedangkan sisanya 39,09\% diterangkan oleh faktor-faktor lain yang tidak diteliti seperti brand image, promosi, kualitas pelayanan, dan lainnya.

3. Berdasarkan hasil uji persamaan regresi antara variabel brand awareness (X) memiliki pengaruh terhadap variabel keputusan pembelian (Y) PT Gramedia Asri Media Cabang Cinere Mall Depok, Hasil analisis tersebut dapat disusun model persamaan regresi linier berganda sebagai berikut: $\mathrm{Y}=15,891+0,804 \mathrm{X}$ yang artinya :

a. Konstanta (a): 15,891, nilai konstanta bernilai positif jika skor variabel brand awareness berarti skor keputusan pembelian akan semakin meningkat.

b. Koefisien (b): 0,804, koefisien variabel keputusan pembelian bernilai positif artinya pengaruh brand awareness terhadap keputusan pembelian PT Gramedia Asri Media Cabang Cinere Mall Depok adalah bersifat positif. Jika skor brand awareness meningkat, maka keputusan pembelian akan semakin meningkat.

Berdasarkan penelitian yang telah dilakukan, didapatkan beberapa saran yaitu sebagai berikut:

1. Sebaiknya bagi perusahaan untuk kedepannya brand awareness dapat ditingkatkan dan dapat dipertahankan lagi dengan cara memberikan pelayanan yang maksimal dan menjaga suasana toko agar lebih nyaman sehingga hal tersebut mampu menunjang kemajuan dimasa yang akan datang agar menghasilkan perubahan tingkatan yang baru dari brand awareness dan pengaruh yang baik untuk keputusan pembelian.

2. Karena hasil yang didapat dari brand awareness terhadap keputusan pembelian adalah 60,9\% maka sebaiknya perusahaan dapat memaksimalkan lagi faktor-faktor yang dapat meningkatkan brand awareness, seperti menggencarkan iklan, promosi 
yang dapat memaksimalkan kesadaran merek PT Gramedia Asri Media Cabang Cinere Mall Depok.

\section{DAFTAR PUSTAKA}

Abdullah, \& Tantri. (2018). Manajemen Pemasaran. Depok: PT RajaGrasindo Persada. Angga, B., Fauzi, A., \& Arifin, Z. (2017). ( Survei pada Pelanggan Produk Aqua 600ml di Indomaret J1 . Raya Candi V Malang ). Jurnal Administrasi Bisnis, 51(1), 96104. Retrieved from

http://administrasibisnis.studentjournal.ub.ac.id/index.php/jab/article/viewFile/211 $2 / 2504$

Arief, Suyadi, \& Sunarti. (2017). Loyalitas Merek ( Survei pada Warga Kelurahan Penanggungan Konsumen Produk Aqua di Kota Malang ). Jurnal Administrasi Bisnis, 44(1), 144-153. Retrieved from http://administrasibisnis.studentjournal.ub.ac.id/index.php/jab/article/viewFile/173 $9 / 2118$

Arikunto. (2013). Prosedur Penelitian: Suatu Pendekatan Praktik. Jakarta: Rineka Cipta.

Hasbun dan Ruswanty. (2016). Komperasi Antara Kelompok Yang Melihat Iklan dan Tidak Melihat Iklan Dengan Moderasi Brand Awareness Terhadap Niat Beli (Studi Pada Commuter Line), 2(1). Retrieved from http://journal.uta45jakarta.ac.id/index.php/jbsuta/article/viewFile/371/pdf

Hery. (2019). Manajemen Pemasaran. Jakarta: Grasindo.

Krisnawati, D. (2016). Pengaruh Brand Awareness Terhadap Keputusan Pembelian AMDK Merek Aqua ( Studi Pada Masyarakat di Kota Bandung ), 4(1). Retrieved from http://ojs.ekonomi-unkris.ac.id/index.php/JMBK/article/view/30/pdf

Lubis, \& Hidayat, R. (2017). Pengaruh Citra Merek dan Harga terhadap Keputusan Pembelian pada Sekolah Tinggi Ilmu Manajemen Sukma Medan. Jurnal Ilman, 5(1), 15-24. $\quad$ Retrieved from http://journals.synthesispublication.org/index.php/ilman\%0APengaruh Mamahir, Soegoto, \& Tumbuan, D. (2015). Mobil Toyota All New Yaris Pada, 15(05). Nurhidayati, \& Yuliantari. (2018). Analisis Pengaruh Kepuasan Pelanggan Terhadap Loyalitas Pelanggan pada Fish Streat Cabang Tebet, II(1), 69-75. Retrieved from 
http://ejournal.bsi.ac.id/ejurnal/index.php/widyacipta/article/view/2918

Paregkuan, Tumbel, D., \& Wenas. (2014). Analisis Pengaruh Brand Image dan

Celebrity Endorsment Terhadap Keputusan Pembelian Produk Shampo Head And Shoulders di 24 Mart Manado, 2(3), 1792-1802. Retrieved from https://ejournal.unsrat.ac.id/index.php/emba/article/view/5972

Roisah,Riris dan Riana, D. (2016). Telaah hubungan citra merek, kualitas produk dan keputusan pembelian konsumen, IV(1), 100-107. Retrieved from http://ejournal.bsi.ac.id/ejurnal/index.php/ecodemica/article/view/351/pdf

Siahaan, \& Yuliati. (2016). Pengaruh Tingkat Brand Awareness Terhadap Keputusan Pembelian Produk Victoria's Secret ( Studi Pada Konsumen Victori a's Secret di PVJ Bandung ), 3(1), 497-505. Retrieved from https://scholar.google.co.id/scholar?hl=id\&as_sdt=0\%2C5\&as_ylo=2014\&as_yhi= 2019\&q=analisis+tingkat+brand+awareness+terhadap+keputusan+pembelian+prod uk+victoris $\% 27 \mathrm{~s} \& b t n G=$

Siregar. (2015). Statistika Terapan Untuk Perguruan Tinggi. Jakarta: PT Kharisma Putra Utama.

Sugiyono. (2013). Metode Penelitian Pendidikan Pendekatan Kuantitatif, Kualitatif, dan $R \& D$. Bandung: Alfabeta. .(2017). Metode Penelitian Kuantitatif, Kualitatif, dan R\&D. Bandung: Alfabeta.

Syahril, R. (2017). Pengaruh motivasi dan gaya hidup konsumen terhadap keputusan pembelian handphone android, VIII(September), 192-199. Retrieved from http://ejournal.bsi.ac.id/ejurnal/index.php/jkom/article/view/3100

Utomo, I. W. (2017). Pengaruh Brand Image, Brand Awareness, dan Brand Trust Terhadap Brand Loyality Pelanggan Online Shopping ( Studi Kasus Karyawan Di BSI Pemuda ), VIII, 76-84. Retrieved from http://ejournal.bsi.ac.id/ejurnal/index.php/jkom/article/view/2327/1607 